\title{
Unsafe Abortion: Changing Pattern of an Avoidable Tragedy
}

\author{
Agrawal A ${ }^{1}$, Regmi MC ${ }^{1}$, Rijal P1, Uprety DK ${ }^{1}$, Agrawal J ${ }^{2}$ \\ ${ }^{1}$ Department of Obstetric and Gynaecology, Department of Pediatrics and Adolescent Medicine, B.P. Koirala Institute of \\ Health Sciences, Dharan.
}

Received: February 13, 2015 ; Accepted: August 25, 2015

\begin{abstract}
Aims: The study was done to analyze current trend of unsafe abortion.
Methods: It was a prospective study where all the abortion related admissions from January 2009 to December 2011 , in Obstetrics and Gynaecology unit at B.P. Koirala Institute of Health Sciences were analyzed. Sixty-six women with diagnosis of unsafe abortion were enrolled in the study. Cases of unsafe abortion were identified and classified using the classification developed by The South African National Incomplete Abortion Study conducted in 1994. Morbidity pattern was compared among the patients using the above classification system.
\end{abstract}

Results: There were 66 cases of unsafe abortion admitted in three years. Most common mode of unsafe abortion was by taking different types of oral drugs in various doses prescribed by medical shops, in $65.2 \%$ of women. Most common clinical presentation was heavy vaginal bleeding in $77 \%$ of women. After evaluation, commonest diagnosis made was incomplete abortion in $56.1 \%$ of women. In $57.6 \%$ of women, unsafe abortion was of low grade. In previous similar study done at the same centre, $16(22.8 \%)$ of unsafe abortions were of low grade, $17(24.2 \%)$ were of moderate grade and $37(52.8 \%)$ were of high grade.

Conclusions: Unsafe abortion is still a significant medical and social problem. The mode of unsafe abortion, presentation and morbidity has changed significantly in recent years. However the morbidity pattern of unsafe abortion is going towards low grade.

Keywords: maternal morbidity; maternal mortality; unsafe abortion.

\section{INTRODUCTION}

Modeled estimates of maternal mortality for 2010 based on socioeconomic determinants show a substantial decline in maternal deaths over the last two decades. ${ }^{1}$ However, there are countless many in South Asia and Sub-Saharan Africa who suffer adverse pregnancy outcomes hindering the commitment to achieve Millennium Development Goal 5. Unsafe abortion still is an important contributing factor to maternal morbidity and mortality and is a major public health concern. Preventing unsafe abortions would contribute substantially towards achieving Millennium Development Goal 5. ${ }^{1}$ The accumulated evidence shows that the removal of restrictions on abortion results in the reduction of maternal mortality due to unsafe abortion and, thus, in the reduction of the overall level of maternal mortality. ${ }^{2,3}$

The World Health Organization defines unsafe abortion as a procedure for terminating an unintended

\section{CORRESPONDENCE}

Dr Ajay Agrawal

Department of Obstetric and Gynaecology, B.P. Koirala Institute of Health Sciences, Dharan.

Email: pshrestha76@gmail.com

Phone: +977- 9852049451 pregnancy either by persons lacking the necessary skills or in an environment lacking the minimal medical standards or both. ${ }^{4}$ As long as women become pregnant unintentionally, and when they cannot continue the pregnancy for whatever reason, they will seek an abortion whether or not the termination of pregnancy is safe in their particular circumstance. However, number of induced abortions declined worldwide between 1995 and 2003, from nearly 46 million to approximately 42 million. ${ }^{5}$ Over the past two decades, the health evidence, technologies and human rights rationale for providing safe and comprehensive abortion care have evolved greatly. In South-Eastern Asia, 14\% of maternal deaths are due to unsafe abortion contributing to maternal mortality ratio of 30 per 100000 live births. ${ }^{5}$ Deaths due to unsafe abortion are mainly caused by severe infections or bleeding resulting from the unsafe abortion procedure, or due to organ damage. The estimated case-fatality rate (deaths per 100000 unsafe abortion procedures) ranges from a high of 750 per 100000 in Sub-Saharan Africa to 10 per 100000 in developed regions, with 100 per 100000 for SouthEast Asia. ${ }^{5}$ 
Nepal has legalized safe abortion since 2004 which is now available in all 75 districts and has also recently legalized medical abortion and $2^{\text {nd }}$ trimester abortion up to 18 gestational weeks with mental health indications. After legalization, women now have access to safe abortion services and their likelihood of dying as a result of an abortion performed with modern methods should be no more than one per 100,000 procedures. $^{4}$ However, access to safe abortion services remains difficult for many Nepali women. Women may be unaware that safe abortion services are legally available, even under limited circumstances. Similarly, they may lack the resources, time or decision-making power to avail themselves of such services or the services may be inadequate to meet their demand. ${ }^{6}$ In a descriptive study done from April 2005 to September 2008 (3.5years), there were 1071 abortion related admissions in gynaecology unit of B.P. Koirala Institute of Health Sciences (BPKIHS) out of which 70 were of unsafe abortions. Unsafe abortion accounted for $14.5 \%$ of maternal mortality during that period. ${ }^{7}$

Patterns of unsafe abortion are critical for tailoring effective interventions to prevent unsafe abortion and for providing post-abortion care. This study aims to understand the dimensions and dynamics of unsafe abortion in the changed approaches and strategies, in view of impact of law and available services, in order to sensitize local health personnel and health planners for the problem as well as to build a database for respective interventions.

\section{METHODS}

BPKIHS is a tertiary care teaching hospital at eastern part of Nepal serving around five million people of eastern Nepal and people from Indian border also come to seek medical services and is one of the referral centers. Yearly admission at Obstetrics and Gynaecology unit of BPKIHS is about 1200. We conducted a descriptive observational study to understand the current pattern of unsafe abortion.

We prospectively analyzed all the abortion related admissions from January 2009 to December 2011 at Obstetrics and Gynaecology Unit of BPKIHS. Among them women with diagnosis of unsafe abortion as per WHO definition were selected using purposive sampling methods. Their demographic information, presenting complaints, place and method of unsafe abortion and management in hospital was recorded.
Women enrolled in the study were also classified using the morbidity severity categories classification developed by The South African National Incomplete Abortion Study conducted in $1994 .{ }^{8}$ We also took account of duration of hospital stay, MICU admission, blood transfusion, total number of maternal death at the same period according to severity of unsafe abortion and calculated the contribution of unsafe abortion in maternal mortality.

Data were analyzed using the statistical program SPSS, version 16.0 (SPSS Inc, Chicago, IL, USA). Qualitative data were presented as frequencies and percentages. Frequency analysis was done for the numerical variables. This study was conducted after taking ethical clearance from ethical review board of BPKIHS. Informed consent was obtained from women enrolled in the study.

\section{RESULTS}

In the study period of three years, there were 788 admissions related to different type of miscarriage at Obstetrics and Gynaecology unit of BPKIHS. Out of these, 66 women were admitted with diagnosis of unsafe abortion making $8.37 \%$ of abortion related admission. Mean age of women was $29.47 \pm 6.7$ years. Twenty (30\%) women were multi gravida. Only $10(15 \%)$ women gave history of previous induced abortion for unwanted pregnancy. Thirtyfive $(53 \%)$ women stated completed family as reason for termination of pregnancy. Twelve (18\%) women underwent termination as they were currently unmarried or had multiple sex partners. Other reasons cited by the women were failure of contraception in $8(12.1 \%)$, short spacing $8,(12.1 \%)$ and social problems $3(4.5 \%)$. Forty $(60 \%)$ women had not used contraception beforehand and those who used were coitus interruptus, which has its own limitation.

When women were asked about the place of attempted termination of pregnancy, most commonplace indicated by them was home by $27(40.9 \%)$ women. The most common method ie 27 , (40.9\%) cases attempted termination of pregnancy by buying drugs from medical shop. Private clinic run by para-medical person and doctors was another site for 21(31.8\%) women. Quacks and faith healers were chosen by five $(7.6 \%)$ each. Regarding method of termination of pregnancy, drugs were used by forty-three (65.2\%) of women, out of whom 39 (90\%) women used oral drug 
and $4(10 \%)$ women used vaginal drugs. Among them thirty-four $(80 \%)$ women had used either mifepristone or misoprostol or both in various regimens. All the women had taken drugs without prescription or counseling. Instrumentation like manual vacuum aspiration and dilatation and curettage was used by fourteen $(21.2 \%)$ of women. Vaginal and oral herbal drugs were used by $9(13.6 \%)$ women. On the basis of attempted method of termination of pregnancy, women were distributed into three groups i.e. Group 1- Use of drugs (oral/vaginal), Group 2- vaginal instrumentation and Group 3- herbal medicine, in our study.

Most common presenting complaint was excessive vaginal bleeding in $51(77.3 \%)$ women followed by pain in lower abdomen in 30 (42.4\%) women. Other complaints were as shown in (Table 1).

Table 1. Presentation of women with unsafe abortion $(n=66)$.

\begin{tabular}{|lll|}
\hline Symptoms & No of women & $\mathbf{( \% )}$ \\
\hline $\begin{array}{l}\text { Excessive vaginal } \\
\text { bleeding }\end{array}$ & 51 & $(77.3)$ \\
Pain in lower abdomen & 30 & $(42.4)$ \\
Fever & 11 & $(16.7)$ \\
Vomiting & 7 & $(10.6)$ \\
$\begin{array}{l}\text { Foul smelling vaginal } \\
\text { discharge }\end{array}$ & 5 & $(7.6)$ \\
Abdominal distension, & 4 & $(6.1)$ \\
Loss of consciousness & 3 & $(4.5)$ \\
Shortness of breath & 2 & $(3)$ \\
\hline
\end{tabular}

Most common diagnosis made was incomplete abortion in 37 (56.1\%) women. Second common diagnosis was pelvic peritonitis in 12 (18.2\%) women. There was uterine perforation with peritonitis in $4(6 \%)$ women. Three $(4.5 \%)$ women presented with ruptured ectopic pregnancy and $3(4.5 \%)$ with inevitable abortion. Two women presented with continued viable intrauterine pregnancy (Table 2).
Table 2. Diagnosis at presentation on the basis of method of attempted abortion $(\mathrm{n}=66)$.

\begin{tabular}{|c|c|c|c|}
\hline Diagnosis (n) & $\begin{array}{l}\text { Drugs } \\
(n=43)\end{array}$ & $\begin{array}{l}\text { Instru- } \\
\text { mentation } \\
(n=14)\end{array}$ & $\begin{array}{l}\text { Herbal } \\
\text { medicine } \\
(n=09)\end{array}$ \\
\hline $\begin{array}{l}\text { Incomplete } \\
\text { Abortion (37) }\end{array}$ & $28(65.1 \%)$ & $05(35.7 \%)$ & $04(44.4 \%)$ \\
\hline $\begin{array}{l}\text { Pelvic } \\
\text { peritonitis (12) }\end{array}$ & $03(7.0 \%)$ & $04(28.6 \%)$ & $05(55.6 \%)$ \\
\hline $\begin{array}{l}\text { Uterine } \\
\text { rupture (6) }\end{array}$ & $06(14.0 \%)$ & $00(0.0 \%)$ & $00(0.0 \%)$ \\
\hline $\begin{array}{l}\text { Generalized } \\
\text { peritonitis (1) }\end{array}$ & $01(2.08 \%)$ & $00(0.0 \%)$ & $00(0.0 \%)$ \\
\hline MODS (1) & $01(2.3 \%)$ & $00(0.0 \%)$ & $00(0.0 \%)$ \\
\hline $\begin{array}{l}\text { Uterine } \\
\text { perforation (4) }\end{array}$ & $00(0.0 \%)$ & $03(21.4 \%)$ & $01(11.1 \%)$ \\
\hline $\begin{array}{l}\text { Hypovolemic } \\
\text { shock (1) }\end{array}$ & $00(0.0 \%)$ & $01(7.1 \%)$ & $00(0.0 \%)$ \\
\hline $\begin{array}{l}\text { Ruptured ectopic } \\
\text { pregnancy (3) }\end{array}$ & $01(2.3 \%)$ & $02(14.2 \%)$ & $00(0.0 \%)$ \\
\hline $\begin{array}{l}\text { Inevitable } \\
\text { abortion (3) }\end{array}$ & $02(4.6 \%)$ & $00(0.0 \%)$ & $01(11.1 \%)$ \\
\hline $\begin{array}{l}\text { Continued } \\
\text { pregnancy (2) }\end{array}$ & $02(4.6 \%)$ & $00(0.0 \%)$ & $00(0.0 \%)$ \\
\hline
\end{tabular}

About $50 \%$ of women were anaemic at presentation and needed blood transfusion. Average unit of blood transfusion needed was $2 \pm 0.6$ units.

Treatment given for these women is shown in Table 3.

Table 3. Distribution of intervention done on the basis of method of attempted abortion $(n=66)$.

\begin{tabular}{|llll|}
\hline $\begin{array}{l}\text { Intervention } \\
\text { done }\end{array}$ & $\begin{array}{l}\text { Drugs } \\
(\mathrm{n}=43)\end{array}$ & $\begin{array}{l}\text { Instrumentation } \\
(\mathrm{n}=14)\end{array}$ & $\begin{array}{l}\text { Herbal } \\
\text { medicine } \\
(\mathrm{n}=09)\end{array}$ \\
\hline MVA/D\&C & $\begin{array}{l}31 \\
(72.1 \%)\end{array}$ & $06(42.9 \%)$ & $08(88.9 \%)$ \\
Laparotomy & $\begin{array}{l}04 \\
(9.3 \%)\end{array}$ & $05(35.7 \%)$ & $1(11.1 \%)$ \\
Conservative & $\begin{array}{l}08 \\
(18.6 \%)\end{array}$ & $03(21.4 \%)$ & $0(0.0 \%)$ \\
\hline
\end{tabular}

Laparotomy was needed for 10 (15.2\%) women and procedures done are shown in Table 4. 
Table 4. Surgical treatment of complicated unsafe abortion done $(\mathrm{n}=10)$.

\begin{tabular}{|ll|}
\hline Surgical Intervention $(\mathbf{n}=\mathbf{1 0})$ & No(\%) \\
\hline $\begin{array}{l}\text { Repair of bowel and } \\
\text { bladder injury }\end{array}$ & $04(40)$ \\
$\begin{array}{l}\text { Repair of uterine } \\
\text { perforation }\end{array}$ & $03(30)$ \\
$\begin{array}{l}\text { Peritoneal lavage } \\
\text { Hysterectomy }\end{array}$ & $02(20)$ \\
\hline
\end{tabular}

Median duration of hospital stay was $3 \pm 0.25$ days. Six women were admitted in maternal intensive care unit. Sixty-four women (97\%) were cured and discharged to home. There were two maternal deaths during the study period among enrolled women. Diagnosis and management of women were also distributed against the attempted method termination of pregnancy (Table 2 and 3). Most common diagnosis among women in group 1 was incomplete abortion in 28 $(65.1 \%)$ women followed by uterine rupture in $6(14 \%)$ women. There were no cases of uterine perforation peritonitis in this group. In group 2, only $5(35.7 \%)$ women had incomplete abortion while pelvic peritonitis and uterine perforation peritonitis was present in four $(28.6 \%)$ and three $(21.4 \%)$ women respectively. In group 3 only 4 (44.4\%) women had incomplete abortion. In this group most common diagnosis was pelvic peritonitis in $5(55.6 \%)$ women. In group-1, 31 (72.1\%) women underwent manual vacuum aspiration (MVA). Among women in group-2, 5 (35.7\%) women underwent laparotomy while only one woman in group-3 underwent laparotomy. More complications like renal and respiratory failure were present in group-3 (2, 22.2\%) and group-2 $(2,14.3 \%)$ group. Women were also categorized according to morbidity severity category of unsafe abortion. ${ }^{8}$ Women in low, moderate and high grade of unsafe abortion were 38 (57.6\%), 15 $(22.7 \%)$ and $13(19.7 \%)$ respectively (Table 5).

Table 5. Distribution of category of unsafe abortion on the basis of method of attempted abortion $(n=61)$.

\begin{tabular}{|llll|}
\hline $\begin{array}{l}\text { Category } \\
\text { of } \\
\text { unsafe } \\
\text { abortion }\end{array}$ & $\begin{array}{l}\text { Drugs } \\
(\mathbf{n = 4 3 )}\end{array}$ & $\begin{array}{l}\text { Instrumen } \\
\text { tation } \\
(\mathbf{n}=\mathbf{1 4})\end{array}$ & $\begin{array}{l}\text { Herbal } \\
\text { medicine } \\
(\mathbf{n = 0 9})\end{array}$ \\
\hline Low (38) & $\begin{array}{l}32 \\
(74.4 \%)\end{array}$ & $04(28.6 \%)$ & $02(22.2 \%)$ \\
Moderate (15) & $\begin{array}{l}06 \\
(14.0 \%)\end{array}$ & $04(28.6 \%)$ & $05(55.6 \%)$ \\
High (13) & $\begin{array}{l}05 \\
(11.6 \%)\end{array}$ & $06(42.9 \%)$ & $02(22.2 \%)$ \\
\hline
\end{tabular}

On distribution of women in different category of unsafe abortion, according to method of attempted abortion, women of group 1 were more in low grade of unsafe abortion $(\mathrm{N}=32,74.4 \%)$. Among women in group-3, 5 women $(55.6 \%)$ were in moderate category of unsafe abortion while only $2(22.2 \%)$ women were in low group. In group-2, 6 (42.9\%) women were in high grade of unsafe abortion. Regarding need of blood transfusion, more women in group-1 needed blood transfusion $(n=32,74.4 \%)$. In group 3 all women needed ventilator support while none of them needed ventilator support in group 1. Both the women who died were of high grade of unsafe abortion.

\section{DISCUSSION}

As long as unintended pregnancy continues, women will continue to seek termination. Women may suffer severe morbidity and mortality if the skill of the healthcare provider and the methods used for termination are inadequate. In present study, 8.4\% of total admissions under miscarriage were of unsafe abortion. In a study done at the same center, unsafe abortion accounted for $6.5 \%$ of total abortion related admission between 2005 April to 2008 September. ${ }^{7}$ This shows that the incidence of unsafe abortion remains almost same in these two periods. Mean age of women in our study was $29.47 \pm 6.7$ years which is similar to WHO estimates of Asian age of unsafe abortion. ${ }^{5}$ In the present study, termination was performed by skilled medical personnel in the majority of women; only $7.6 \%$ women went to faith healers and quacks. Similarly, one community-based survey in rural India found that most of the providers were medically trained. ${ }^{9}$ Also, mode of attempted termination in this study was use of oral or vaginal drugs by $65.2 \%$ of women. Out of these, $80 \%$ had taken various dose and regimen of either mifepristone or misoprostol or both. All the women had taken the drugs without prescription and proper counseling. This demonstrates the changing pattern of mode of attempts to terminate pregnancy as compared to previous study where history was not revealed by $60 \%$ of the patients and $13(19 \%)$ women used herbal sticks and twigs inserted through the vagina for termination of the pregnancy. ${ }^{7}$

Reason for termination of pregnancy was unwanted pregnancy for $68(97.1 \%)$ women in previous study ${ }^{7}$ which is not consistent with present study where completed family was commonly cited reason for 
termination of pregnancy in $35(53 \%)$ women. Other social reasons and failure of contraception were other stated reasons by women in this study. Similar observations were made by Bhutta et al. in Karachi in 2003 , where $50 \%$ of the patients were married multiparous women who did not want more children and had termination. ${ }^{10}$ In this study, out of 66 women with unsafe abortion, 38 (57.6\%) women were in low grade, $15(22.7 \%)$ moderate and $13(19.7 \%)$ in high grade of unsafe abortion. It was inconsistent with previous study where, $16(22.8 \%)$ were of low grade, $17(24.2 \%)$ were of moderate grade and 37 (52.8\%) were of high grade. ${ }^{7}$ This demonstrates, changing pattern of unsafe abortion with decrease in morbidity severity of unsafe abortion.

In the current study larger number of patients were admitted with low grade of unsafe abortion, hence, systemic complications were present in only 5 women. In the previous study systemic complications were present in $70 \%$ of the patients. ${ }^{7}$ Blood transfusion was needed in $56 \%$ of the patients in our previous study while $80 \%$ of the patients needed blood transfusion in present study indicating more women coming with vaginal bleeding with resulting anemia requiring blood transfusion. Median duration of hospital stay in our study was $3 \pm 0.25$ days which was significantly less compared to mean duration of hospital stay of 7.4 days in previous study. ${ }^{7}$ Moreover due to decrease in severity of unsafe abortion and the resulting systemic complications, requirement for intensive care unit (ICU) admissions was also reduced. ICU care was required for 20 patients out of which 13 required ventilator and inotropic support in previous study, ${ }^{7}$ while only 6 women needed ICU admission with one requiring ventilator support in current study.

\section{REFERENCES}

1. Building a Future for Women and Children The 2012 Report. [cited 2012 July 22] available from http://www. countdown2015mnch.org/reports-and-articles/2012-report.

2. David HP. Abortion in Europe, 1920-91: a public health perspective. Stud Fam Plann 1992;23:1-22.

3. Jewkes R, Brown H, Dickson K, Levin J, Rees H. Prevalence of morbidity associated with abortion before and after legalisation in South Africa. BMJ. 2002;324(7348):1252-3.

4. Grimes D, Benson J, Singh S Grimes D, Benson J, Singh S, Romero M, Ganatra B, Okonofua F et al. Unsafe Abortion; the preventable pandemic. Lancet. 2006;368:1908-19.

5. World Health Organization. Unsafe abortion: global and regional estimates of the incidence of unsafe abortion and associated mortality in 2003. 5th ed. Geneva: World Health Organization; 2007.
WHO estimates that unsafe abortion accounts for $13 \%$ of maternal mortalities in low-resource countries. ${ }^{4}$ However, in the present study unsafe abortion contributed to 2 per $43(4.7 \%)$ of maternal death during the study period. This demonstrates a significant decrease in maternal mortality due to unsafe abortion.

\section{CONCLUSIONS}

There is a change in pattern of unsafe abortion observed from use of herbs leading to sepsis to using drugs leading to incomplete abortion and anemia. The most common method of unsafe abortion is improper regimen of medical abortion drugs either by selfmedication due to easy availability of over the counter drugs or improper prescription by pharmacies. Therefore, upgrading the knowledge of pharmacists and paramedics is of paramount importance to reduce unsafe abortion. Moreover, providing information and services for modern contraception is the primary prevention strategy to eliminate unplanned pregnancy and hence unsafe abortions. Inclusion of more tertiary centre as well as community level health centre may forecast more on the true picture of changing pattern of unsafe abortion which may be a focus for future research.

\section{ACKNOWLED GEMENTS}

We thank Dr Reshu Agrawal Sagtani who performed quality assurance checks and helped in analysis.

\section{DISCLOSURE}

The authors report no conflicts of interest in this work.

No violation of human rights and safety.

Funding: Nil

6. Iyengar K, Iyengar SD. Elective abortion as a primary health service in rural India: experience with manual vacuum aspiration. Reproductive Health Matters. 2002;10(19):54-63.

7. Regmi MC, Rijal P, Subedi SS , Uprety D, Budathoki B, Agrawal A. Unsafe abortion: a tragic saga of maternal suffering. J Nepal Med Assoc. 2010;49(177):19-22.

8. Rees H, Katzenellenbogen J, Shabodein R. The epidemiology of incomplete abortion in South Africa. S Afr Med J. 1997;87:432-37.

9. Ramachandar L, Pelto PJ. Abortion providers and safety of abortion: a community based study in a rural district of Tamil Nadu, India. Reprod Health Matters. 2004Nov;12(24 Suppl):138-46.

10. Bhutta SZ, Aziz S, Korejo R. Surgical complications following unsafe abortion. J Pak Med Assoc. 2003;53(7):286-9. 